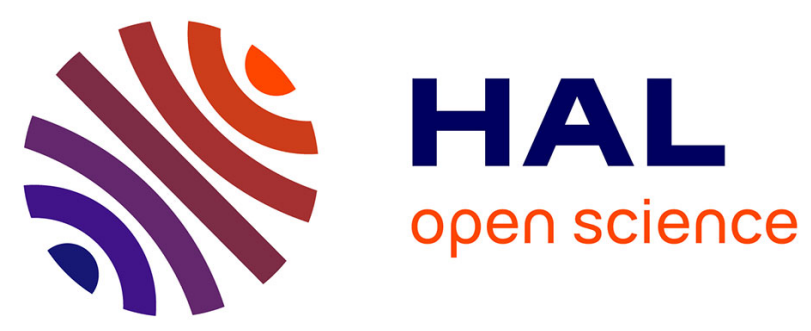

\title{
Lifetime Stability and Microstructure Properties of Cr/B4C X-ray Reflective Multilayer Coatings
}

Catherine Burcklen, Regina Soufli, Jennifer Rebellato, Christopher Walton, Evgueni Meltchakov, Julien Rault, Eric Gullikson, Franck Delmotte

\section{- To cite this version:}

Catherine Burcklen, Regina Soufli, Jennifer Rebellato, Christopher Walton, Evgueni Meltchakov, et al.. Lifetime Stability and Microstructure Properties of Cr/B4C X-ray Reflective Multilayer Coatings. Journal of Nanoscience and Nanotechnology, 2019, 19 (1), pp.554 - 561. 10.1166/jnn.2019.16480 . hal-01909382

\section{HAL Id: hal-01909382 \\ https://hal.science/hal-01909382}

Submitted on 21 Nov 2018

HAL is a multi-disciplinary open access archive for the deposit and dissemination of scientific research documents, whether they are published or not. The documents may come from teaching and research institutions in France or abroad, or from public or private research centers.
L'archive ouverte pluridisciplinaire HAL, est destinée au dépôt et à la diffusion de documents scientifiques de niveau recherche, publiés ou non, émanant des établissements d'enseignement et de recherche français ou étrangers, des laboratoires publics ou privés. 


\title{
Lifetime Stability and Microstructure Properties of $\mathrm{Cr} / \mathrm{B}_{4} \mathrm{C}$ X-ray Reflective Multilayer Coatings
}

\author{
Catherine Burcklen ${ }^{1}, *$, Regina Souflii, ${ }^{1}$, Jennifer Rebellato ${ }^{2}$, Christopher Walton ${ }^{1}$, Evgueni Meltchakov ${ }^{2}$, \\ Julien E. Rault ${ }^{3}$, Eric Gullikson ${ }^{4}$, and Franck Delmotte ${ }^{2}$ \\ ${ }^{1}$ Lawrence Livermore National Laboratory, 7000 East Avenue, Livermore, California 94550, USA \\ ${ }^{2}$ Laboratoire Charles Fabry, Institut d'Optique Graduate School, CNRS, Université Paris-Saclay, 91127 Palaiseau Cedex, France \\ ${ }^{3}$ Synchrotron SOLEIL, CNRS-CEA, L'Orme des Merisiers, Saint-Aubin-BP48, 91192 Gif-sur-Yvette, France \\ ${ }^{4}$ Center for X-ray Optics, Lawrence Berkeley National Lab, 2-400, Berkeley, California 94720, USA
}

\begin{abstract}
This paper demonstrates that highly reflective $\mathrm{Cr} / \mathrm{B}_{4} \mathrm{C}$ multilayer interference coatings with nanometric layer thicknesses, designed to operate in the soft X-ray photon energy range, have stable reflective performance for a period of 3 years after deposition. The microstructure and chemical composition of layers and interfaces within $\mathrm{Cr} / \mathrm{B}_{4} \mathrm{C}$ multilayers is also examined, with emphasis on the $\mathrm{B}_{4} \mathrm{C}$-on-Cr interface where a significant diffusion layer is formed and on the oxide in the top $\mathrm{B}_{4} \mathrm{C}$ layer. Multiple characterization techniques (X-ray reflectivity at different photon energies, $\mathrm{X}$-ray photoelectron spectroscopy, transmission electron microscopy, electron diffraction and X-ray diffraction) are employed and the results reveal a consistent picture of the $\mathrm{Cr} / \mathrm{B}_{4} \mathrm{C}$ layer structure.
\end{abstract}

Keywords: Multilayers, Soft X-rays, Chrominum, Boron Carbide.

\section{INTRODUCTION}

$\mathrm{Cr} / \mathrm{B}_{4} \mathrm{C}$ has been proven to be among the highest performing metal/ $\mathrm{B}_{4} \mathrm{C}$ multilayer interference coatings, ${ }^{1}$ from the EUV $^{2}$ to the $\mathrm{X}-$ ray $^{3}$ ranges, for applications including solar physics, astronomy, photolithography, synchrotron optics, plasma diagnostics and X-ray microscopy. $\mathrm{Cr} / \mathrm{B}_{4} \mathrm{C}$ is of particular interest at photon energies in the vicinity of the $\mathrm{Cr}$ and $\mathrm{B}$ absorption edges, as illustrated in Figure 1, which shows the peak reflectance of optimized $\mathrm{Cr} / \mathrm{B}_{4} \mathrm{C}$ multilayers as a function of photon energy around the $\mathrm{B} \mathrm{K}$ edge and the $\mathrm{Cr} \mathrm{L}$ and $\mathrm{K}$ edges. The reflectance values shown in Figure 1 are based on a model obtained from actual measurements on $\mathrm{Cr} / \mathrm{B}_{4} \mathrm{C}$ multilayers ${ }^{1}$ and thus correspond to values one could reasonably obtain in practice.

In general, the best peak reflectance can be expected for photon energies right below an absorption edge, benefitting from a significant reduction in absorption of one of the constituent materials in the multilayer. More specifically, $\mathrm{B}_{4} \mathrm{C}$ can be used as the "spacer" material below the B K edge $(188 \mathrm{eV})$, leading to a $\mathrm{Cr} / \mathrm{B}_{4} \mathrm{C}$ peak reflectance as high as $29 \%$ at $187 \mathrm{eV}$ near normal incidence and $37 \%$ at a grazing incidence angle of $33.6 \mathrm{deg}$. Near the $\mathrm{Cr} \mathrm{L}$ edge

*Author to whom correspondence should be addressed.
$(574 \mathrm{eV})$, the relatively low absorption in both $\mathrm{Cr}$ and $\mathrm{B}_{4} \mathrm{C}$ combined with a high contrast in refractive indices allow the peak reflectance to increase up to almost $58 \%$ at an energy of $573 \mathrm{eV}$ and a grazing angle of $9.2 \mathrm{deg}$. Below the $\mathrm{Cr} \mathrm{K}$ edge $(5989 \mathrm{eV})$, the very low absorption and good contrast again lead to very high peak reflectance, up to $89 \%$ at a 2 deg grazing incidence angle.

Through the analysis of reflectivity measurements at several photon energies and electron microscopy images, previous work ${ }^{1}$ revealed a layer structure in $\mathrm{Cr} / \mathrm{B}_{4} \mathrm{C}$ multilayers with the presence of a significant interfacial layer due to interdiffusion at the $\mathrm{B}_{4} \mathrm{C}$-on- $\mathrm{Cr}$ interface. Hence, magnetron- and ion beam-sputtered $\mathrm{Cr} / \mathrm{B}_{4} \mathrm{C}$ multilayers (with $\mathrm{Cr}$ layers in the $1.87-2.82 \mathrm{~nm}$ range and $\mathrm{B}_{4} \mathrm{C}$ layers in the $1.2-5.4 \mathrm{~nm}$ range) were simulated with a 3-layer model made of a pure $\mathrm{Cr}$ layer, a $1-1.5 \mathrm{~nm}$ thick interdiffusion layer (IL) and a pure $\mathrm{B}_{4} \mathrm{C}$ layer. Other multilayers with thinner $\mathrm{B}_{4} \mathrm{C}$ layers (in the $0.72-1.08 \mathrm{~nm}$ range) revealed that the $\mathrm{B}_{4} \mathrm{C}$ layer was fully intermixed with the $\mathrm{Cr}$ layer and were thus simulated with a 2-layer model including a pure $\mathrm{Cr}$ layer and an interdiffusion layer, indicating that the amount of $\mathrm{B}_{4} \mathrm{C}$ in the multilayer may not be sufficient to form a pure $\mathrm{B}_{4} \mathrm{C}$ layer. ${ }^{1}$ The exact nature of this interfacial layer has not been fully elucidated. Another 


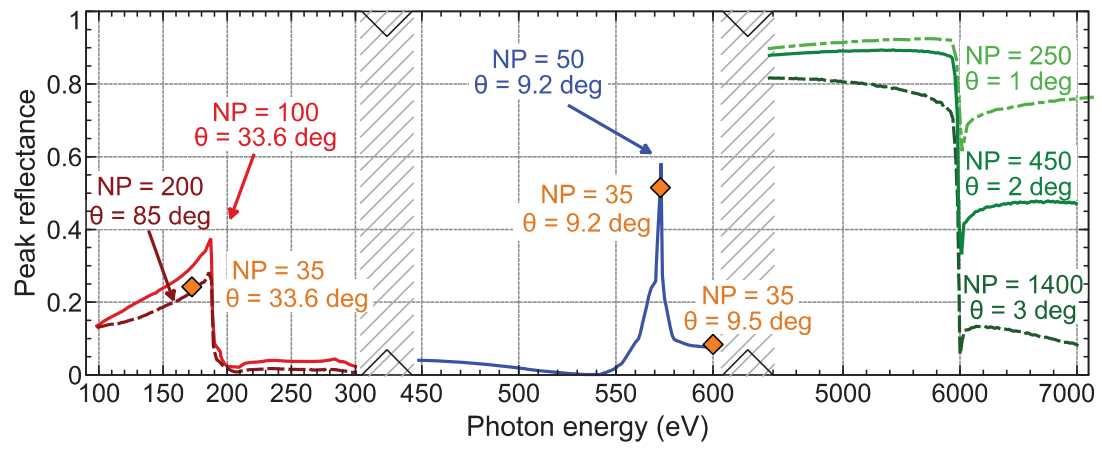

Figure 1. Peak reflectance of optimized $\mathrm{Cr} / \mathrm{B}_{4} \mathrm{C}$ multilayers (solid and dash lines) as a function of photon energy. The data points (diamonds) indicate the measured reflectance of sample MS1, discussed in Ref. [1] and later in this paper. The model used to simulate the multilayer performance was deduced from actual measurements and is also discussed in Ref. [1].

concern is the influence this interfacial layer may have on the $\mathrm{Cr} / \mathrm{B}_{4} \mathrm{C}$ multilayer aging properties, which is a crucial factor toward the fabrication of efficient and stable coatings.

In an effort to address the above questions, in this paper we present the first study of temporal stability properties of $\mathrm{Cr} / \mathrm{B}_{4} \mathrm{C}$ multilayers with layer thicknesses in the nanoscale range, over a period of 3 years after deposition. The microstructure and chemical composition of layers within $\mathrm{Cr} / \mathrm{B}_{4} \mathrm{C}$ multilayers is also elucidated. The characterization techniques employed include Grazing Incidence X-ray Reflectometry (GIXR) with $\mathrm{Cu} \mathrm{K} \alpha$ radiation and Soft X-ray Reflectometry (SXR) at several wavelengths as well as X-ray Photoelectron Spectroscopy (XPS), transmission electron microscopy (TEM), electron diffraction and X-ray diffraction.

\section{EXPERIMENTAL SETUP}

The multilayer samples discussed in this paper have been deposited by magnetron sputtering (MS) and by ion beam sputtering (IBS). The details of the deposition processes are described in a recent publication ${ }^{1}$ and previous papers. $^{4,5}$

The BRUKER ${ }^{\circledR}$ Discover D8 grazing incidence X-ray (GIXR) reflectance measurement apparatus at $8 \mathrm{keV}$ at LCF has been described in Ref. [1].

The details of the ALS measurements are described in a recent publication. ${ }^{1}$ The ALS X-ray beam was $92.8 \%$ s-polarized at $170 \mathrm{eV}$ and $92.7 \%$ s-polarized at $172.4 \mathrm{eV}$ in the 2017 measurements; in the 2014 measurements, the beam was $90.1 \%$ s-polarized at $170 \mathrm{eV}$ and $172.4 \mathrm{eV}$.

The XPS experiments were carried out on the CASSIOPEE beamline of the SOLEIL synchrotron, in the HR-ARPES (High-Resolution Angle-resolved PhotoEmission Spectroscopy) endstation, using a photon energy of $900 \mathrm{eV}$. The photon source was a HU60 Apple II undulator set to deliver linearly polarized light in the $100 \mathrm{eV}-$ $1500 \mathrm{eV}$ energy range. The size of the incident photon beam was $100 \times 200 \mu \mathrm{m}^{2}$. The energy resolution was
$300 \mathrm{meV}$ and the angular resolution was $0.25^{\circ}$. During the XPS measurements, the photoelectrons were detected by a Scienta R4000 hemispherical electron analyzer. The Fermi level reference was taken from the spectra of the valence band of each sample. A "Shirley background" was subtracted in all core level spectra. The B1s spectra were fitted by Gaussian curves.

Transmission Electron Microscopy (TEM) measurements were performed at EAG Labs (Sunnyvale, California). Prior to TEM imaging, the samples were prepared by Focused Ion Beam (FIB). TEM imaging was performed with a Tecnai TF20 instrument with a field emission gun and $0.2 \mathrm{~nm}$ spatial resolution. Highresolution images were obtained by using all the orders in the diffraction pattern. Selected Area Diffraction (SAD) images were obtained by using a 200-nm aperture on bright field TEM images (which were obtained by selecting the central diffraction order only). Dark field (DF) images were obtained by selecting a small area on the electron diffraction pattern using an appropriate aperture.

Large Angle X-ray Diffraction (LAXRD) and Grazing Incidence X-ray Diffraction (GIXRD) measurements were performed using a Panalytical Xpert Pro MRD equipped with a $\mathrm{Cu} \mathrm{K} \alpha$ anode, a W/Si mirror and a $0.5 \mathrm{deg}$ divergence slit. For the LAXRD setup, both the sample angle $\theta$ and detector angle $2 \theta$ were scanned. With the GIXRD setup, the sample angle as compared to the incident beam was fixed to the value of $\theta=0.4 \mathrm{deg}$, while the detector angle $2 \theta$ was scanned.

\section{LIFETIME STABILITY}

We investigated the aging properties of three $\mathrm{Cr} / \mathrm{B}_{4} \mathrm{C}$ multilayers studied in a previous work: ${ }^{1}$ samples MS1, MS2 and IBS1. MS1 and MS2 were deposited using magnetron sputtering and IBS1 by ion beam sputtering. The sample parameters (layer thicknesses and number of bilayers) are gathered in Table I. The lifetime stability study was performed by comparing recent SXR and GIXR reflectance measurements to the same type of measurements done 
Table I. Model parameters for 2017 data for samples MS1, MS2, IBS1. The thicknesses are in $\mathrm{nm}$. NP is the number of periods (bilayers). "Top $\mathrm{B}_{4} \mathrm{C}$ " refers to the top-most $\mathrm{B}_{4} \mathrm{C}$ layer in the multilayer structure. " $\mathrm{B}_{2} \mathrm{O}_{3}$ " refers to the oxide thickness on top of the multilayer.

\begin{tabular}{lccccccc}
\hline Sample & Period & NP & Cr & IL & $\mathrm{B}_{4} \mathrm{C}$ & Top $\mathrm{B}_{4} \mathrm{C}$ & $\mathrm{B}_{2} \mathrm{O}_{3}$ \\
\hline MS1 & 6.70 & 35 & 1.53 & 1.50 & 3.67 & 3.67 & 1.10 \\
MS2 & 6.80 & 10 & 1.63 & 1.50 & 3.67 & 2.24 & 1.33 \\
IBS1 & 5.92 & 10 & 2.47 & 1.10 & 2.35 & 1.11 & 1.15 \\
\hline
\end{tabular}

three years earlier (a few months after multilayer deposition). During that 3-year period, the samples were stored in plastic containers, in air and at room temperature.

The SXR reflectance versus incidence angle was measured in 2014 and 2017 around the Boron K-edge at a photon energy of $172.4 \mathrm{eV}$ for MS1 and MS2, and at $170 \mathrm{eV}$ for IBS1. The 2017 measurements were performed at ALS, whereas in 2014, MS1 was measured both at ALS and SOLEIL, and MS2 and IBS1 at SOLEIL only. ${ }^{1}$ Figure 2 shows a comparison of the reflectance measurements from 2014 (black dashed lines) and 2017 (solid lines) for all samples. One can notice that the overall shape of the measured data from 2017 is very similar to the data from 2014 for all samples. One can observe the presence of Bragg peaks precisely at the expected positions (33.6 deg for MS1, $33.1 \mathrm{deg}$ for MS2 and $39.2 \mathrm{deg}$ for IBS1). The peak reflectance in 2017 is very close to the one measured in 2014: in 2017 (2014), we measured a peak reflectance of $25.1 \%(24.2 \%), 10.6 \%(10.8 \%)$ and $7.3 \%$ (7.4\%) for MS1, MS2 and IBS1 respectively.

The increase in reflectance for MS1 may be partially attributed to the change in polarization. Whereas the beam was $90.1 \%$ s-polarized in 2014, the s-polarization coefficient has grown to $92.7 \%$ in 2017 . However, this polarization change does not fully explain the reflectance rise for MS1, which may be attributed to the modification of the top surface. On the other hand, MS2 and IBS1 saw

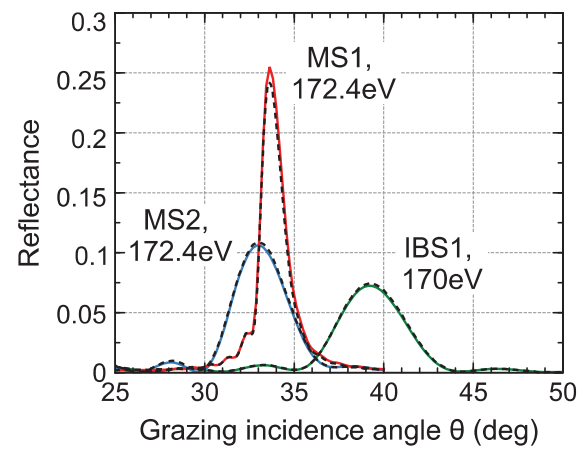

Figure 2. Measured reflectance as a function of grazing angle at a photon energy of $172.4 \mathrm{eV}$ (samples MS1 and MS2) and $170 \mathrm{eV}$ (sample IBS1). The curves in dashed black lines correspond to the data measured in 2014 shortly after multilayer deposition (at ALS for MS1 and SOLEIL for MS2 and IBS1). The solid lines represent the data measured in 2017 at ALS (3 years after deposition). their peak reflectance slightly decrease over time with a similar change in polarization. Note that despite the fact that MS2 and IBS1 were initially measured on a different synchrotron (SOLEIL), their reflectance spectrum was well-reproduced at ALS after a period of three years.

The reflectance curves measured in 2017 were modeled in order to investigate in detail the multilayer sample aging. The fitted layer thicknesses for all samples are given in Table I and a comparison of the measured versus simulated reflectance is shown in Figure 3. The simulations are represented by the black solid lines and the data points show the measured reflectance from 2017. One can see that the simulations fit the measurements quite well. The models used to simulate the samples in 2017 are identical to the 2014 models, ${ }^{1}$ except for the very top layers. As reported in Table I, only the oxide and top-most $\mathrm{B}_{4} \mathrm{C}$ layer thicknesses have been modified in order to account for the variation in peak reflectance. For MS1, the increase in reflectance is consistent with a growth of the oxide layer from $0.5 \mathrm{~nm}^{1}$ to $1.1 \mathrm{~nm}$. As for MS2 and IBS1, the decrease in peak reflectance may be explained by a combination of the oxide layer growth (from $0.5 \mathrm{~nm}$ to $1.33 \mathrm{~nm}$ for MS2 and from $0.6 \mathrm{~nm}$ to $1.15 \mathrm{~nm}$ for IBS1) and a reduction of the top-most $\mathrm{B}_{4} \mathrm{C}$ layer, consistent with the consumption of $\mathrm{B}_{4} \mathrm{C}$ to form the oxide layer. The remaining top $\mathrm{B}_{4} \mathrm{C}$ layer after oxide formation appears to be different between samples MS1 and MS2. It is likely that there are subtle differences in the top oxide contamination layer between the two samples that we were not able to capture in our model.

All three samples were also measured in 2017 on the same GIXR setup as in 2014 (See Section 2). As an example, the measured reflectance for MS1 is plotted in Figure 4. The experimental curve from 2017 (blue dots in Fig. 4) is almost identical to the data from 2014 (green triangles). In particular, the critical angle remains at the same position as in 2014, indicating that the average composition of the multilayer has not evolved. The Bragg peaks

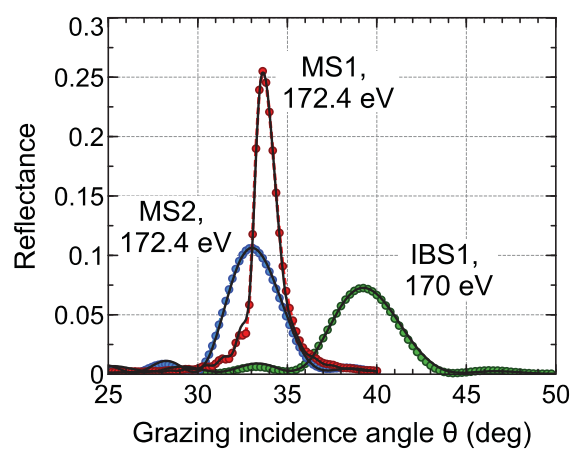

Figure 3. Measured (points) and simulated (black solid lines) reflectance as a function of grazing incidence angle at a photon energy of $172.4 \mathrm{eV}$ (samples MS1 and MS2) and $170 \mathrm{eV}$ (sample IBS1). The points represent the data measured in 2017 at ALS (3 years after multilayer deposition). 


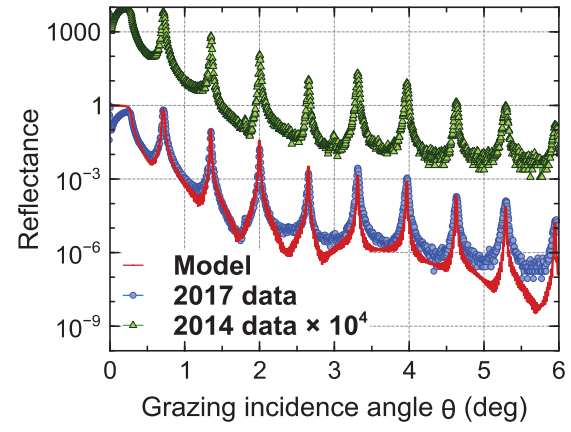

Figure 4. Simulated (red solid line) and measured (points) GIXR reflectance from sample MS1 at a photon energy of $8048 \mathrm{eV}$. The green triangles represent the data measured right after deposition in 2014 and have been shifted on the $y$-axis, for better visibility. The blue circles show the reflectance measured in 2017, three years after deposition.

have stayed very well-defined over the three year-period and remained at the same positions. This demonstrates the stability of the multilayer, since it kept a very good periodic structure and the period thickness has not changed in three years. The only notable difference between the experimental curves from 2014 and 2017 is the shape of the Kiessig fringes in-between the 2nd and 3rd Bragg orders, due to the formation of oxide on the top surface.

The GIXR reflectance has been simulated using the same model as the one that was used for the SXR data (see Table I and Fig. 3). The GIXR model is plotted in
Figure 4 (red solid line) with the corresponding experimental GIXR data. One can observe that the new model with modified top layers describes very well the shape of the measured curve between the second and third Bragg orders. Hence, the growth of the oxide layer appears to be consistent with both the SXR data at $172.4 \mathrm{eV}$ and the GIXR data at $8048 \mathrm{eV}$. Similar observations were made for MS2 (GIXR data and simulation not shown here).

$\mathrm{Cr} / \mathrm{B}_{4} \mathrm{C}$ multilayers thus seem to have undergone very little alteration after 3 years of aging. They appear to be very stable, provided that the $\mathrm{B}_{4} \mathrm{C}$ capping layer is thick enough, e.g., thicker than $2.5 \mathrm{~nm}$, as evidenced in Table I. Based on the three multilayer samples studied in this section, the top $\mathrm{B}_{4} \mathrm{C}$ layer seems to have limited the oxidation and has prevented it from propagating through the whole multilayer structure.

\section{XPS}

In order to obtain a more detailed picture of the chemical composition of the top layers in aged $\mathrm{Cr} / \mathrm{B}_{4} \mathrm{C}$ multilayers, XPS spectra were measured on sample MS2, 3 years after deposition, and on a $\mathrm{B}_{4} \mathrm{C}$ thin film sample (about $48 \mathrm{~nm}$ thick), 7 years after deposition. The latter was used as a "reference" sample, representative of a well-aged $\mathrm{B}_{4} \mathrm{C}$ thin film exposed to air. XPS data were obtained on both samples for 2 photoelectron exit angles: normal incidence
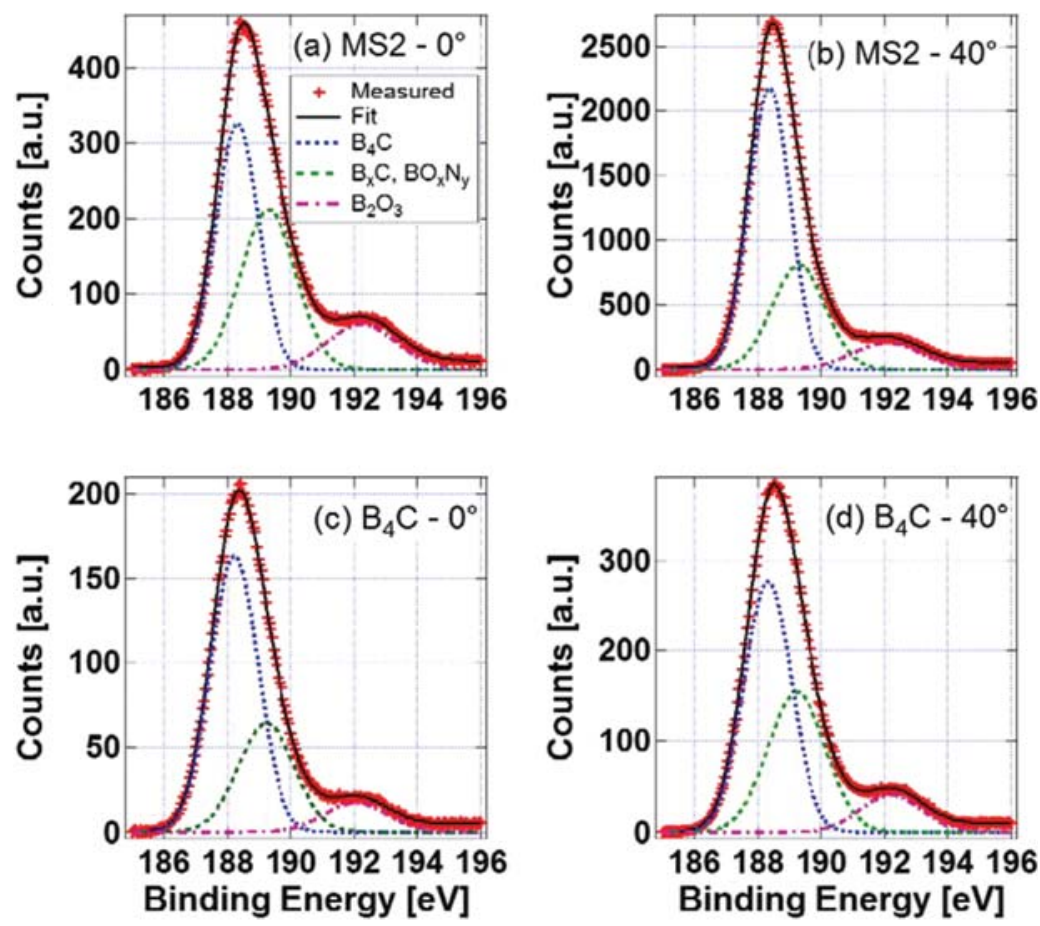

Figure 5. XPS B1s spectra measured on: (a, b), the MS2 sample and (c, d), on a $\mathrm{B}_{4} \mathrm{C}$ thin film at two different exit angles: $0^{\circ}$ (a, c) and $40^{\circ}$ (b, d). Fits with 3 gaussian components are also plotted. 
$\left(0^{\circ}\right)$ and $40^{\circ}$ off-normal. The main features that appeared in low-resolution, survey scans from 0 up to $700 \mathrm{eV}$ (not shown here) for both samples are $\mathrm{B} 1 s, \mathrm{C} 1 s$ and $\mathrm{O} 1 s$ and (a low-intensity) N1s lines. Additional low-intensity Cr3p and $\mathrm{Cr} 2 s$ lines appeared for the MS2 sample. The presence of $\mathrm{O}$ and $\mathrm{N}$ species can be attributed to the surface contamination/oxidation. No other species were detected in these survey spectra.

Figure 5 shows high resolution XPS spectra around the B1s line for both samples and both exit angles. All experimental spectra were fitted with 3 Gaussian distribution curves centered at $188.30 \pm 0.08 \mathrm{eV}, 189.27 \pm$ $0.04 \mathrm{eV}$ and $192.16 \pm 0.09 \mathrm{eV}$ with full width at half maximum of about $1.6 \mathrm{eV}, 2.1 \mathrm{eV}$ and $2.5 \mathrm{eV}$, respectively. These fits with 3 components are in good agreement with previous measurements reported on magnetron sputtered $\mathrm{B}_{4} \mathrm{C}$ thin films. ${ }^{8}$ The component with the lowest binding energy $(\sim 188.3 \mathrm{eV})$ was attributed to boron as $\mathrm{B}_{4} \mathrm{C}$ while the component with the highest energy $(\sim 192 \mathrm{eV})$ was attributed to oxidized boron, such as $\mathrm{B}_{2} \mathrm{O}_{3}$. The component with intermediate binding energy $(\sim 189 \mathrm{eV})$ can be attributed to boron-depleted boron carbide $\left(\mathrm{B}_{x} \mathrm{C}\right)$, or boron suboxide $\left(\mathrm{BO}_{x}\right)$, or boron oxynitride $\left(\mathrm{BO}_{x} \mathrm{~N}_{y}\right)$. The relative peak area corresponding to each component is given in Table II.

The probed depth was estimated from tabulated values of photoelectron mean free paths. ${ }^{9}$ It varies from about $5.7 \mathrm{~nm}$ for $0^{\circ}$ to about $4.3 \mathrm{~nm}$ for $40^{\circ}$ off-normal. Figure 6 shows a schematic of the layer stack model of the top portion of MS2, as determined from SXR measurements (see Section 3), with the depth of each interface indicated. One can see in Figure 6 that the measurement of $\mathrm{B} 1 s$ at $40^{\circ}$ probes mainly the top oxide $\left(\mathrm{B}_{2} \mathrm{O}_{3}\right)$ and $\mathrm{B}_{4} \mathrm{C}$ layers whereas the measurement at $0^{\circ}$ probes also the interfacial layer (IL).

Concerning the measurement at $0^{\circ}$, one can notice a significant increase of the $\mathrm{B}_{x} \mathrm{C}, \mathrm{BO}_{x} \mathrm{~N}_{y}$ component for sample MS2, as compared to a $\mathrm{B}_{4} \mathrm{C}$ thin film (Figs. 5(a) and (c) and Table II). According to the MS2 model (Fig. 6), this additional signal comes from the IL. The spectra measured on MS2 display also an increased $\mathrm{B}_{2} \mathrm{O}_{3}$ content as compared to the $\mathrm{B}_{4} \mathrm{C}$ sample. This indicates that the top oxide layer is thinner on the $\mathrm{B}_{4} \mathrm{C}$ sample or that Oxygen is present in the top IL and/or Cr layers in MS2 sample.

For the $\mathrm{B}_{4} \mathrm{C}$ sample, the peak area of the $\mathrm{B}_{x} \mathrm{C}, \mathrm{BO}_{x} \mathrm{~N}_{y}$ and $\mathrm{B}_{2} \mathrm{O}_{3}$ components increases at $40^{\circ}$ (Fig. 5(d)) as

Table II. Relative peak area of the 3 components used to fit the XPS results (see Fig. 5).

\begin{tabular}{lcccc}
\hline Sample & $\begin{array}{c}\text { Angle } \\
(\text { deg})\end{array}$ & $\begin{array}{c}\mathrm{B}_{4} \mathrm{C} \text { peak } \\
\text { area }(\%)\end{array}$ & $\begin{array}{c}\mathrm{B}_{x} \mathrm{C}, \mathrm{BO}_{x} \mathrm{~N}_{y} \\
\text { peak area }(\%)\end{array}$ & $\begin{array}{c}\mathrm{B}_{2} \mathrm{O}_{3} \text { peak } \\
\text { area }(\%)\end{array}$ \\
\hline $\mathrm{Cr} / \mathrm{B}_{4} \mathrm{C}-\mathrm{MS} 2$ & 0 & 46.1 & 39.8 & 14.1 \\
$\mathrm{Cr} / \mathrm{B}_{4} \mathrm{C}-\mathrm{MS} 2$ & 40 & 60.8 & 29.6 & 9.6 \\
$\mathrm{~B}_{4} \mathrm{C}-\mathrm{MP09061}$ & 0 & 62.3 & 29.0 & 8.7 \\
$\mathrm{~B}_{4} \mathrm{C}-\mathrm{MP09061}$ & 40 & 53.3 & 36.5 & 10.2 \\
\hline
\end{tabular}

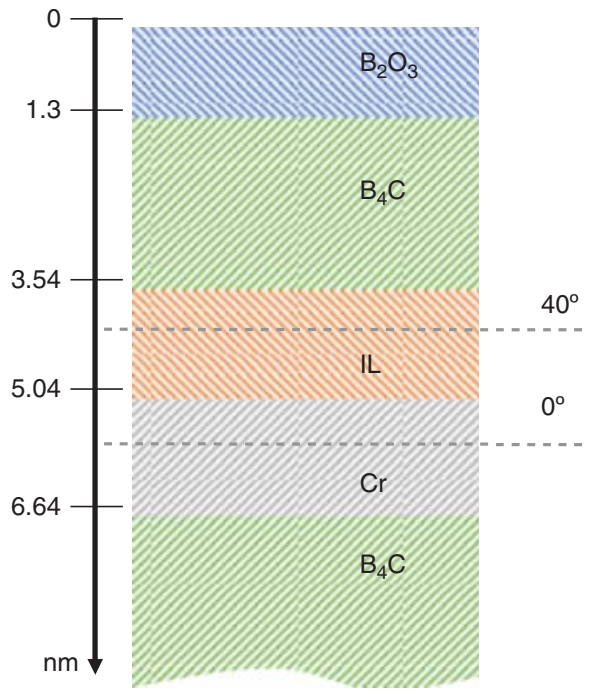

Figure 6. Schematic drawing of the top of portion of the MS2 multilayer, based on the model obtained from SXR measurements in Section 3. Dashed lines represent an estimation of probe depths for two XPS exit angles $\left(0^{\circ}\right.$ and $40^{\circ}$ off-normal)

compared to $0^{\circ}$. This clearly shows that these components are present in the top surface of the $\mathrm{B}_{4} \mathrm{C}$ sample. On the contrary, for the MS2 sample, these two components decrease when the exit angle is more grazing (Fig. 5(b)). This confirms that these components are present in the IL layer and are responsible for a significant part of the signal measured at $0^{\circ}$.

In conclusion, the XPS measurements of B1s spectra on MS2 sample at 2 different exit angles, and comparison with a $\mathrm{B}_{4} \mathrm{C}$ thin film sample, are consistent with the model determined for MS2 by SXR and GIXR analyses (Figs. 3, 4). More specifically, the XPS measurements validate the presence of the IL layer (inferred by the SXR and GIXR measurements), by revealing an XPS signature that is different from that of the $\mathrm{B}_{4} \mathrm{C}$ layer. The IL layer may contain $\mathrm{B}_{x} \mathrm{C}, \mathrm{BO}_{x}$, or $\mathrm{BO}_{x} \mathrm{~N}_{y}$; a small amount of $\mathrm{Oxy}-$ gen may also be present in the topmost $\mathrm{Cr}$ layer.

\section{MICROSTRUCTURE INVESTIGATION}

Two $\mathrm{Cr} / \mathrm{B}_{4} \mathrm{C}$ samples were selected for microstructure analysis with TEM: sample MS1 (see Section 3 and Table I) and MS3, which is the same as MS1, with the exception of the $\mathrm{B}_{4} \mathrm{C}$ thickness. The targeted $\mathrm{B}_{4} \mathrm{C}$ thickness was $1.08 \mathrm{~nm}$ in MS3 versus $5.4 \mathrm{~nm}$ in MS1, before interdiffusion was taken into account. It has been previously evidenced ${ }^{1}$ that there were no pure $\mathrm{B}_{4} \mathrm{C}$ layers left in sample MS3, due to extensive interdiffusion occurring at the $\mathrm{B}_{4} \mathrm{C}$-on- $\mathrm{Cr}$ interfaces, leading to the $\mathrm{B}_{4} \mathrm{C}$ layers being entirely consumed at the interfaces. As a result, the SXR reflectance from sample MS3 measured shortly after deposition, was almost zero. SXR and GIXR reflectance data from MS3 were simulated by employing a two-layer model 
made of a $1.35-\mathrm{nm}$ thick $\mathrm{Cr}$ layer and a 1.65 -nm thick, Cr-rich interlayer (IL), which had a slightly different composition than the interface layer present in the MS1 sample. As a reminder, per Table I, MS1 was modeled with $\mathrm{Cr}$, $\mathrm{IL}$ and $\mathrm{B}_{4} \mathrm{C}$ layer thicknesses of $1.53,1.50$ and $3.67 \mathrm{~nm}$, respectively. Sample MS3 does not have any practical utility (owing to its near-zero reflectance), nevertheless, its layer and interface physics remain intriguing, since its asdeposited $\mathrm{B}_{4} \mathrm{C}$ thickness of $1.08 \mathrm{~nm}$ seems to be below the limit needed to produce a pure $\mathrm{B}_{4} \mathrm{C}$ layer inside the $\mathrm{Cr} / \mathrm{B}_{4} \mathrm{C}$ multilayer. The opposite seems to be the case for sample MS1. Therefore, we chose to study samples MS1 and MS3 by TEM, side-by-side.

Figure 7 shows high-resolution, $800 \mathrm{~K}$ magnification TEM images of samples MS1 (Fig. 7(a)) and MS3 (Fig. 7(b)), obtained about 7 months after deposition. The MS1 high resolution TEM image shows smooth interfaces and well-defined layers. Some darker regions are visible within the Cr layers; they may correspond to polycrystalline $\mathrm{Cr}$, as will be discussed later in this section. $\mathrm{B}_{4} \mathrm{C}$ layers look amorphous and one can see "mediumgray" layers, corresponding to the interfacial layers at the $\mathrm{B}_{4} \mathrm{C}$-on-Cr interfaces, which are much thicker than the Cr-on- $\mathrm{B}_{4} \mathrm{C}$ interfaces. Sample MS3 however exhibits a more "chaotic" layer stack. There is evidence of a periodic structure, but the layers appear dissimilar in both lateral and growth directions and the layer contrast is uneven. One can still observe some dark regions, which could correspond to pure and potentially polycrystalline $\mathrm{Cr}$, but they are discontinuous and do not seem to appear in every period. The apparent thicknesses delineated in Figures 7(a) and (b) for the Cr, $\mathrm{B}_{4} \mathrm{C}$ and IL layers of both samples MS1 and MS3 are consistent with the thicknesses derived by modeling GIXR and SXR data (see Table I and Ref. [1]).

To investigate further the degree of crystallinity in the layers within our $\mathrm{Cr} / \mathrm{B}_{4} \mathrm{C}$ multilayers, MS1 and MS3 were also studied by Selected Area Diffraction (SAD). The SAD pattern for MS1 (resp. MS3) is shown in Figure 8 (Fig. 9). The observations made on the high-resolution images in Figure 7 above were confirmed by the analysis of the electron diffraction patterns. The MS1 SAD pattern (Fig. 8) shows several diffraction spots surrounded by
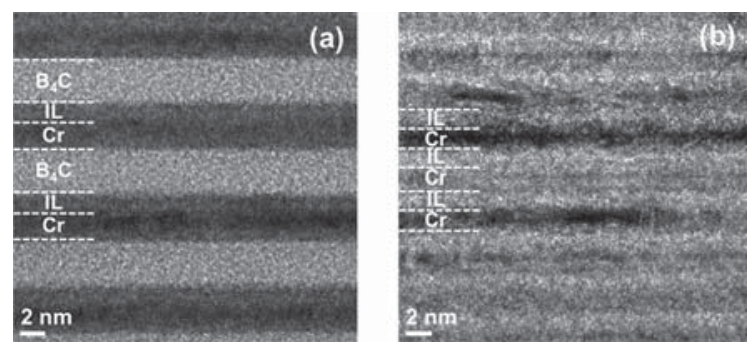

Figure 7. High-resolution TEM images from samples (a) MS1, and (b) MS3, obtained at $800 \mathrm{~K}$ magnification. The white dash lines delineate the apparent $\mathrm{Cr}, \mathrm{B}_{4} \mathrm{C}$ and interdiffusion layers (IL) inside the $\mathrm{Cr} / \mathrm{B}_{4} \mathrm{C}$ multilayer structure.

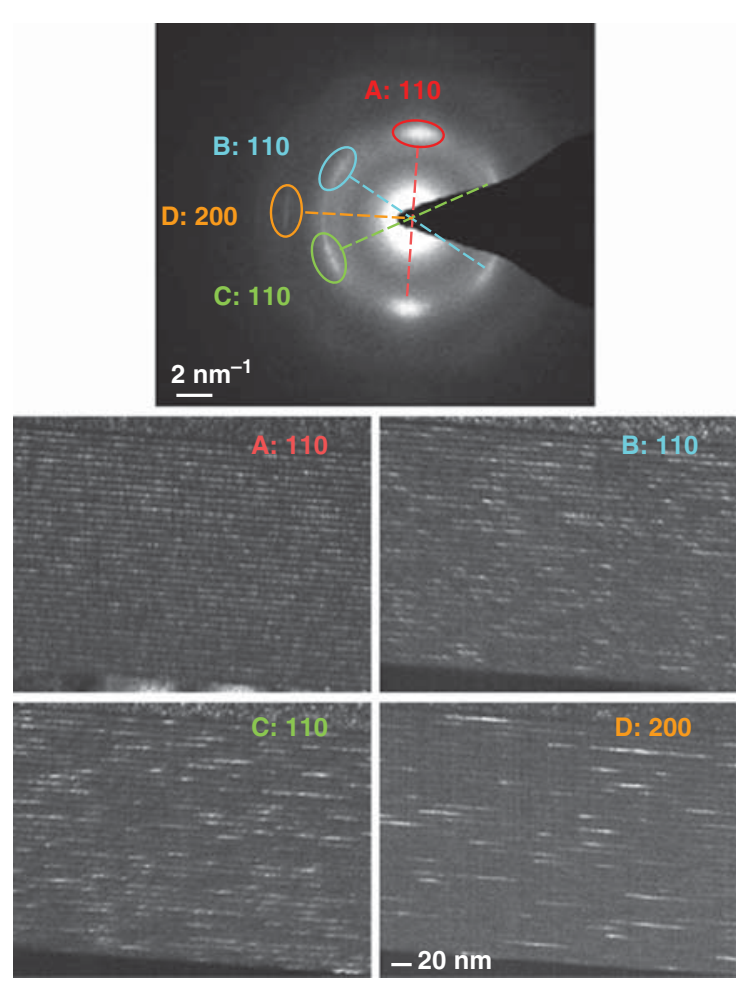

Figure 8. Selected area diffraction image and corresponding dark field images from sample MS1.

a diffuse ring. The spots evidence the presence of polycrystalline species in the multilayer, presumably $\mathrm{Cr}$, which has a bcc (body-centered-cubic) crystalline structure. The spots have an arced shape with a relatively wide dimension in the radial direction, indicating that the crystallites are rather small and their orientation varies around a preferred

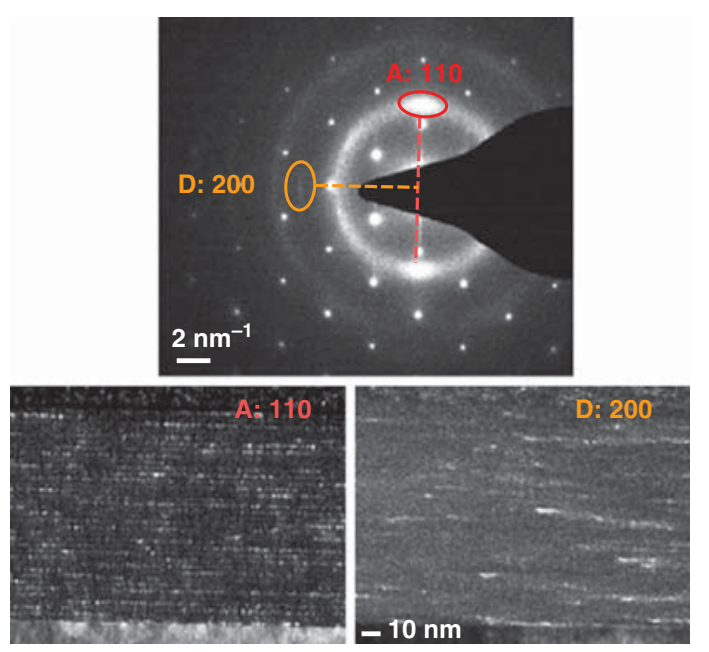

Figure 9. Selected area diffraction image and corresponding dark field images from sample MS3. 
orientation given by the center of the spot. It has been previously observed in the literature ${ }^{10,11}$ that $\mathrm{Cr}$ in thin films produces similar arced spots by electron diffraction analysis.

In order to verify the nature of the crystallites, the electron diffraction pattern was indexed: the distance between diffracting planes was deduced from each spot's position relative to the center (blocked by the black mask), and was then compared to the $\mathrm{Cr}$ bcc-allowed reflections. The three spots marked as A, B and C in Figure 8, and their opposite with respect to the center (see the spots at the tip of the dashed lines) correspond to the same plane family since they are located on the same circle. They correspond to a distance of $2.080 \AA, 2.051 \AA$ and $2.039 \AA \pm 0.007 \AA$ respectively, which is consistent with the $\mathrm{Cr}$ (110) plane spacing $\left(2.040 \AA\right.$ with a lattice constant of $\left.2.885 \AA^{12}\right)$. Spot A corresponds to any rotation of the crystallites, as long as one of their (110) planes is perpendicular to the multilayer growth direction. Spots B and C appear only when the crystallites are rotated so that the electron beam illuminates them towards the (111) plane. Another arced spot is also visible: spot $D$ in Figure 8. It corresponds to a distance of $1.430 \AA \pm 0.006 \AA$ which is consistent with the $\mathrm{Cr}$ (200) plane spacing (1.443 $\AA$ in theory).

The four spots evidenced with the SAD pattern were used to produce Dark Field (DF) images of the multilayer in order to locate the different types of crystallites within the multilayer. Specifically, one can see in the DF image on spot A that the crystallites seem to be present in each $\mathrm{Cr}$ layer across the whole multilayer, meaning that the sample contains strongly textured (110) Cr. The DF image corresponding to spot D shows that the (200) crystallites are much less present and seem to be arranged in bigger clusters, forming thick and very discontinuous zones. This suggests that there is a weak (200) texture.

Similar analysis, shown in Figure 9, was performed on sample MS3. Spot A (distance of $2.084 \pm 0.006 \AA$ ), corresponding to $\mathrm{Cr}(110)$, is still strongly present in the electron diffraction pattern, suggesting there are still (110) oriented crystallites in the multilayer. Spots B $(2.019 \pm$ $0.006 \AA)$ and $C(2.012 \pm 0.006 \AA)$ still seem to be present but are less visible due to the presence of a bright ring at the same distance from the center. There is still an arced spot corresponding to $\mathrm{Cr}(200)$ reflection (spot D, distance of $1.425 \pm 0.006 \AA$ ). Note that the SAD pattern also shows reflections from the $\mathrm{Si}\langle 100\rangle$ substrate, since the aperture diameter was slightly larger than the total multilayer thickness. A second ring appears beyond spot $\mathrm{D}$ and could be consistent with the $\mathrm{Cr}$ (211) reflection (measured distance of $1.174 \pm 0.006 \AA$, in theory $1.177 \AA$ ).

DF images were taken, selecting either spot A or spot D. The DF image on spot A shows crystallites across a majority of the multilayer, but they are not as widely spread in the Cr layers as in sample MS1. Thus the Cr (110) texture in MS3 may be weaker than in MS1. The (200) oriented crystallites form highly irregular and sparse clusters. It may be interesting to note that, although the asdesigned Cr layer thickness is the same $(2.5 \mathrm{~nm})$ for both samples MS1 and MS3, the interdiffusion and formation of the layer IL at the $\mathrm{B}_{4} \mathrm{C}$-on- $\mathrm{Cr}$ interface, depends on the $\mathrm{B}_{4} \mathrm{C}$ thickness and appears to diminish the Cr crystallinity in MS3 (presumably due to the reduced "pure" $\mathrm{Cr}$ layer thickness, remaining after interdiffusion), compared to MS1. It is also noteworthy that the Cr layers in samples MS1 and MS3 maintain a significant degree of crystallinity and texture, despite the fact that $40-50 \%$ of the Cr thickness is consumed at the interlayer IL, leaving "pure" $\mathrm{Cr}$ layers of only $1.53 \mathrm{~nm}$ (MS1) and $1.35 \mathrm{~nm}$ (MS3).

There is no evidence of $\mathrm{B}_{4} \mathrm{C}$ crystallinity in the electron diffraction and DF images for either MS1 or MS3 samples (Figs. 8 and 9), as was also indicated in Figure 7. We thus conclude that the $\mathrm{B}_{4} \mathrm{C}$ layers are nanocrystalline or amorphous, as has also been demonstrated in earlier literature. . $^{8,13}, 14$

Finally, the $\mathrm{Cr} / \mathrm{B}_{4} \mathrm{C}$ multilayer microstructure was investigated by means of $\mathrm{X}$-ray diffraction measurements using two different set-ups: LAXRD and GIXRD. The results are plotted in Figure 10: Figure 10(a) shows LAXRD measurements on samples MS1 and MS3, and on a blank Si $\langle 100\rangle$ wafer; Figure 10(b) shows the GIXRD measurement on sample MS1.

The LAXRD measurement of sample MS1 shows the multilayer Bragg peaks up to the 21st order, demonstrating the remarkable layer and interface quality of that sample. For both samples MS1 and MS3, a broad peak appears for a detector angle $2 \theta$ of approximately $43.5 \mathrm{deg}$. This peak being absent in Si LAXRD data, one can assume it corresponds to crystallinity in the multilayers and not in the substrate, unlike the other peaks between 30 and $35 \mathrm{deg}$, and around $55 \mathrm{deg}$, which also appear in the data from the Si substrate.

The peak's position near $2 \theta=43.5 \mathrm{deg}$ corresponds to a distance of $2.08 \pm 0.05 \AA$ and is thus consistent with

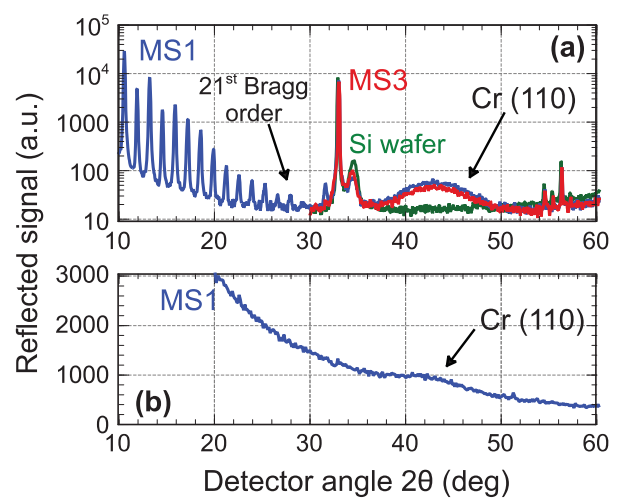

Figure 10. (a) LAXRD (log scale) and (b) GIXRD (linear scale) data are shown. Both MS1 and MS3 samples, as well as a Si wafer substrate, were measured by LAXRD, while sample MS1 only was measured by GIXRD. 
the $\mathrm{Cr}$ (110) plane spacing, computed from the Cr tabulated lattice constant and with the value determined earlier with SAD. The Cr (110) peak is expected to be at around $44.3 \mathrm{deg} ;{ }^{15}$ the angle shift could be attributed to strain in $\mathrm{Cr}$. The Cr (110) peaks exhibit similar height and width for both samples, which might be consistent with the fact that they contain the same amount of Cr. The size of the $\mathrm{Cr}$ crystallites was computed from the LAXRD data in Figure 10(a), via the Scherrer equation. It was found to be $1.26 \pm 0.05 \mathrm{~nm}$ for MS1 and $1.31 \pm 0.05 \mathrm{~nm}$ for MS3, which is comparable to the Cr layer thickness (after interlayer formation) in these two multilayer samples. Finding the crystallite size to be comparable with the layer thickness is typical in sputtered polycrystalline thin films with nanoscale thickness, in a variety of multilayer material systems.

Sample MS1 was also measured by GIXRD (see Fig. 10(b)). The GIXRD set-up allows to remove the substrate contribution in terms of crystallinity peaks: the incident angle is chosen so that the beam does not penetrate all the way to the substrate but it is larger than the critical angle for the beam to enter the multilayer coating. Although the signal is weaker than with the LAXRD set-up and the background prevails, the $\mathrm{Cr}$ (110) peak is also visible on the MS1 GIXRD scan (Fig. 10(b)).

\section{CONCLUSIONS}

The reflectance of short-period $\mathrm{Cr} / \mathrm{B}_{4} \mathrm{C}$ multilayers for the soft X-ray has been measured and analyzed at multiple photon energies and it is found to be stable over a period of 3 years after deposition, thus rendering these coatings suitable for applications requiring long-term stability. The presence and thickness of (i) a significant interfacial layer at the $\mathrm{B}_{4} \mathrm{C}$-on- $\mathrm{Cr}$ interfaces and (ii) an oxide in the topmost $\mathrm{B}_{4} \mathrm{C}$ layer, initially inferred by modeling GIXR and SXR data, are also validated via TEM and XPS analysis techniques. Both the top oxide and the interfacial layers do not appear to evolve significantly in the long term and thus they do not affect the overall reflectance stability. Cr-containing layers within the $\mathrm{Cr} / \mathrm{B}_{4} \mathrm{C}$ multilayer are revealed to be polycrystalline and strongly textured in the (110) orientation while $\mathrm{B}_{4} \mathrm{C}$ layers are amorphous, as demonstrated by TEM, electron diffraction and X-ray diffraction measurements. The evidence of $\mathrm{Cr}$ texture in the $\mathrm{Cr} / \mathrm{B}_{4} \mathrm{C}$ multilayer is remarkable, given that $40 \%$ of the $\mathrm{Cr}$ layer is consumed at the $\mathrm{B}_{4} \mathrm{C}$-on- $\mathrm{Cr}$ interface, and the remaining $\mathrm{Cr}$ layer is only $1.53 \mathrm{~nm}$-thick.

Acknowledgments: This work was performed under the auspices of the U.S. Department of Energy by Lawrence Livermore National Laboratory under Contract No. DE-AC52-07NA27344. Funding was provided in part by the Jean d'Alembert fellowship program from Université Paris-Saclay. All multilayer samples have been deposited as part of CEMOX (Centrale d'Elaboration et de Métrologie d'Optique X), a platform of LUMAT federation (CNRS FR2764).

\section{References and Notes}

1. C. Burcklen, R. Soufli, D. Dennetiere, F. Polack, B. Capitanio, E. Gullikson, E. Meltchakov, M. Thomasset, A. Jérome, S. de Rossi, and F. Delmotte, J. App. Phys. 119, 125307 (2016).

2. S. S. Andreev, A. D. Akhsakhalyan, M. A. Bibishkin, N. I. Chkhalo, S. V. Gaponov, S. A. Gusev, E. B. Kluenkov, K. A. Prokhorov, N. N. Salashchenko, F. Schafers, and S. Y. Zuev, Cent. Eur. J. Phys. 1, 191 (2003).

3. F. Comin, G. Apostolo, A. K. Freund, P. Mangiagalli, M. Navizet, and C. L. Troxel, Proc. SPIE 3448, 11 (1998).

4. J. Gautier, F. Delmotte, M. Roulliay, F. Bridou, M.-F. Ravet, and A. Jérome, Appl. Opt. 44, 384 (2005).

5. A. Ziani, F. Delmotte, C. Le Paven-Thivet, E. Meltchakov, A. Jérome, M. Roulliay, F. Bridou, and K. Gasc, Thin Solid Films 552,62 (2014).

6. J. H. Underwood and E. M. Gullikson, J. Electron Spectrosc. Relat. Phenom. 92, 265 (1998).

7. E. M. Gullikson, S. Mrowka, and B. B. Kaufmann, Proc. SPIE 4343, 363 (2001).

8. R. Soufli, A. L. Aquila, F. Salmassi, M. Fernandez-Perea, and E. M. Gullikson, Appl. Opt. 47, 4633 (2008).

9. NIST Database for the Simulation of Electron Spectra for Surface Analysis (SESSA), https://www.nist.gov/srd/nist-standard -reference-database-100.

10. L. Tang and D. E. Laughlinm, J. Appl. Cryst. 29, 411 (1996).

11. J. Forssell and B. Persson, J. Phys. Soc. Jpn. 29, 1532 (1970)

12. M. E. Straumanis and C. C. Weng, Acta Cryst. 8, 367 (1955).

13. C. Michaelsen, J. Wiesmann, R. Bormann, C. Nowak, C. Dieker, S. Hollensteiner, and W. Jäger, Opt. Lett. 26, 792 (2001).

14. C. Borchers and C. Michaelsen, Philos. Mag. A 82, 1195 (2002).

15. S. L. Duan, J. O. Artman, B. Wong, and D. E. Laughlin, J. Appl. Phys. 67, 4913 (1990).

Received: 16 February 2018. Accepted: 19 July 2018. 